\title{
Múltiplas abordagens teóricas e metodológicas nos estudos de música popular
}

JOSÉ ROBERTO ZAN ${ }^{1}$

A inclusão dos estudos de música popular nos cursos de graduação e pósgraduação em Música, bem como o crescimento, nas últimas décadas, das pesquisas acadêmicas sobre esse tema, colocam a necessidade de aprimoramento constante de referenciais teóricos e metodológicos adequados a esse objeto. Como sabemos, a música popular, tanto instrumental como na modalidade canção, é um fenômeno dotado de grande complexidade, o que se traduz tanto em dificuldades relativas à sua definição e delimitação como em seu caráter multifacetado e multidimensional. Além dos elementos estritamente musicais, a música popular envolve aspectos relativos à performance, à gestualidade e aos efeitos do seu caráter indissociável a um sistema de produção e circulação dotado de um complexo aparato tecnológico vinculado à fonografia, ao cinema, ao rádio, à televisão e às novas mídias; aparato que se encontra em constante transformação. Ao mesmo tempo, como acontece com as demais modalidades artísticas, a música popular está inserida em contextos sócio-históricos e culturais mais amplos, envolvendo questões relativas à memória, à tradição e configurações identitárias. Todos esses elementos são constitutivos da música popular que carrega em seus aspectos formais e nos relacionados a conteúdo as marcas da dinâmica e das contradições sociais. O estudo da música popular como fenômeno cultural e artístico deve, na medida do possível, considerar todas essas dimensões, porém sem perder de vista a primazia do material musical, que, por sua vez, deve ser o ponto de partida e o ponto de chegada de todo

\footnotetext{
${ }^{1}$ Doutorado em Ciências Sociais pela Universidade Estadual de Campinas (1997) e Livre-Docência em Música pela mesma Universidade. Atualmente é professor do Departamento de Música do Instituto de Artes da Universidade Estadual de Campinas.
} 
trabalho investigativo. Para tanto, parece necessário que a pesquisa esteja apoiada numa abordagem interdisciplinar que envolva instrumentais analíticos de vários campos do conhecimento.

Os artigos que compõem esta seção temática para o v. 8 (2021) do presente número da MPR revelam não só a possibilidade, mas também a eficácia do uso de parâmetros teóricos e metodológicos diversos nos estudos acadêmicos da música popular.

\section{Teoria Crítica}

Três desses artigos abordam a música popular a partir da Teoria Crítica formulada pelos filósofos da chamada Escola de Frankfurt, uma proposta teórica que estabelece a interface entre filosofia, psicanálise e teoria social, contrapondo-se à ciência positivista e assumindo uma perspectiva normativa voltada para a crítica das formas de dominação presentes na sociedade contemporânea. Gabriel Sampaio Sousa Lima Rezende, em “Origem e reflexão: minhas experiências de crítica imanente com a música popular", faz a revisão de estudos realizados por ele nos últimos anos, apontando potencialidades e limites das abordagens interdisciplinares. Tendo como principal referência teórica a obra de Walter Benjamin, destaca a importância da crítica imanente como procedimento capaz de revelar o teor de verdade das obras. Ricardo Ribeiro Lira da Silva, em "A teoria crítica da música revisitada: notas sobre a Introdução à sociologia da música de Theodor W. Adorno", retoma o debate sobre teorias fundamentais do filósofo alemão a respeito da posição da música na sociedade contemporânea a partir, principalmente, de uma das suas últimas obras, a Introdução à Sociologia da Música, publicada em 1968, um ano antes da sua morte. O autor destaca que nessa obra, ao retomar conceitos e diagnósticos formulados nos anos de 1930 e 40, Adorno não apenas reafirma o potencial crítico de seus estudos sobre música e sociedade, como também apresenta argumentos que se contrapõem a interpretações enrijecidas e muitas vezes reducionistas de seus trabalhos. Frederico Lyra de Carvalho, no artigo “Improvisação, Identidade e Sistema pelo exterior: a não identidade da música de Steve Coleman através da filosofia de Adorno", busca na Dialética Negativa do filósofo alemão referências para analisar aspectos da obra 
musical de Steve Coleman. O autor demonstra que o vigor da obra de Coleman reside na contradição que se estabelece entre a organização sistemática dos parâmetros musicais no plano das composições e a improvisação que tensiona e cria aberturas nesses sistemas, possibilitando variações e, ao mesmo tempo, impedindo que a estrutura composicional se feche em si mesma.

\section{História e estudos culturais}

Outros artigos estabelecem algum tipo de diálogo com abordagens teóricas interdisciplinares que têm no conceito de cultura um dos pontos centrais. Um conceito de cultura num sentido amplo, não restrita aos estudos tradicionais de obras clássicas, muitas vezes identificadas com obras da alta cultura, mas um conceito muito próximo a abordagens antropológicas, que estende o campo de interesse para as manifestações e práticas culturais de grupos sociais diversos, especialmente de segmentos ou classes populares. Ao mesmo tempo, tais abordagens buscam referências em diversas disciplinas como sociologia, teoria literária, linguística, teorias da comunicação, entre outras. Referimo-nos aos "Estudos Culturais" e à "História Cultural". Os autores de seis dos artigos selecionados para esta seção temática recorrem, cada um a seu modo, a essas construções teóricas para o estudo da música popular. $\mathrm{O}$ artigo de Adalberto Paranhos, "Entre os passos do samba e o compasso da ditadura: fissuras e censura em tempos de Estado Novo", tem como foco a música popular brasileira produzida durante o Estado Novo, regime ditatorial protagonizado por Getúlio Vargas no período de 1937 a 1945. O autor procura demonstrar até que ponto as ações repressivas do Estado, principalmente por meio do Departamento de Imprensa e Propaganda, o DIP, órgão governamental responsável pela censura aos meios de comunicação, obtiveram êxito em calar as vozes dos sambistas, especialmente os que trataram em suas composições de temas que se contrapunham ao ideário dominante naquele contexto político. Ao analisar atentamente um conjunto de sambas gravados naqueles anos que circularam amplamente pelos meios de comunicação (principalmente o rádio), Paranhos demonstra que, além das letras das composições, os arranjos, as instrumentações, as performances vocais e gestuais foram capazes de acrescentar 
significados às canções que conflitavam com o ideário oficial do Estado Novo, principalmente com os padrões morais dominantes e com a ideologia do trabalhismo. Humberto Junqueira, em “O (im)provável encontro entre o Mulato Calado e o Delegado Chico Palha: apontamentos sobre a pesquisa em música no contexto da cultura popular urbana brasileira", parte de uma perspectiva interdisciplinar para tratar do evento musical como prática concreta inserida em contextos complexos de relações sociais que envolvem múltiplos sujeitos e que são ao mesmo tempo marcados por tensões, disputas e conflitos. O autor destaca que os estudos das músicas populares não se limitam aos registros sonoros, mas possibilitam a compreensão de aspectos mais amplos da vida social. Juliana Soares da Costa Silva, em "'A Banda' de Chico Buarque: uma marcha em forma de canção brasileira - sobre o papel do arranjo na ressignificação da canção", concentra sua atenção na gravação dessa composição vencedora do II Festival de Música Popular Brasileira da TV Record de 1966 - feita por Nara Leão, com arranjo de Geny Marcondes. Por meio de consulta a uma ampla documentação, faz uma contextualização detalhada do fonograma, considerando não apenas o ambiente do festival, mas também as circunstâncias políticas e culturais da época. Ao analisar o conteúdo e os aspectos formais da composição, a autora deu ênfase ao papel do arranjo, que, segundo ela, incorporou novas camadas de significado à composição, contribuindo para revelar o conteúdo crítico da canção no contexto político daqueles anos marcados pelo regime ditatorial militar. Daniel Lovisi, em "Paixão e Fé: estudo sobre o processo de significação na canção de Tavinho Moura e Fernando Brant", apoiado na semiótica utilizada pelo musicólogo Philip Tagg, ressalta a presença de signos associados à religiosidade católica na composição, relacionados com o cotidiano das cidades coloniais mineiras e com o universo religioso, signos inscritos nas diversas dimensões da composição, como letra, melodia, timbre, arranjos etc. Victor Fernandes Albergaria e Sérgio Paulo Ribeiro de Freitas, em “Gilberto aqui e agora: lá fora de uma canção de Gil", analisam a canção "Aqui e agora" composta por Gilberto Gil nos dias em que o cantor esteve preso em Curitiba durante a excursão dos Doces Bárbaros pela capital catarinense em 1976. Ao mesmo tempo em que analisam as imbricações entre as dimensões musicais e poéticas da composição, dão ênfase a todo um contexto que circunda a sua produção e circulação para revelarem as 
camadas de significado que a obra adquiriu ao longo do tempo. Renan Branco Ruiz, no texto "A vanguarda paulista instrumental jazz e música popular brasileira instrumental na grande São Paulo (1976-1986)", investiga a formação de grupos musicais dedicados à música instrumental em São Paulo, movimento denominado Vanguarda Paulista Instrumental. O autor procura compreender as tensões existentes na produção desses grupos entre uma sonoridade experimental representada, de um lado, por elementos do jazz fusion, free jazz e música moderna contemporânea e, de outro, por gêneros tradicionais associados à ideia de brasilidade.

\section{História e memória da música popular}

Os artigos que compõem este subconjunto abordam questões relacionadas com a pesquisa histórica e com a memória da música popular brasileira. Flávia Guia Carnevali e José Geraldo Vinci de Moraes, no artigo “Eneida, amor e fantasia: Eneida de Moraes (1904-1971) - militância e feminismo na história do carnaval carioca", analisam o papel da jornalista, contista e memorialista na construção da memória do carnaval da cidade do Rio de Janeiro e do samba. Como militante de esquerda, vinculada ao Partido Comunista Brasileiro, Eneida reconhece na festa popular uma forma de resistência e de projeção utópica. Sua obra contribuiu para a construção da noção de identidade cultural brasileira a partir do popular. Urbano Lemos Junior e Vicente Gosciola, em "A canção popular, a pesquisa folclórica e o legado preservacionista", se dedicam ao estudo da obra da cantora e compositora Elise Houston, que realizou pesquisas de cultura popular em várias regiões do país e deixou um conjunto de gravações de canções de tradição oral reconhecidas como fontes documentais importantes da cultura brasileira. Sandor Buys, no artigo "Discos fonográficos como fonte histórica análise do recém-descoberto selo Apollo, feito pela Casa A Elétrica (1913-1923)", apresenta um conjunto de discos fonográficos descobertos recentemente, lançados pelo selo "Apollo", ou "Disco Apollo", vinculado à Casa A Elétrica, fundada em 1908 pelos irmãos Savério e Emílio Leonetti. São gravações realizadas por meio do sistema mecânico que compõem um importante acervo documental para a história da fonografia no Brasil. 


\section{Globalidade e localidade}

Os dois artigos que seguem resultam de pesquisas sobre gêneros musicais populares que mesmo globalizados se inserem em redes de relações identitárias locais. O texto de Gabriel Barth da Silva, "Sonhos do Oriente: trajetórias de vida e identidades atravessadas pelo K-pop em Curitiba", é um estudo de caso sobre o consumo do gênero musical coreano K-pop na cidade de Curitiba. Trata-se de um gênero globalizado que mescla elementos de outros gêneros, como pop, rock, rap, hiphop e techno, e que circula em plataformas da internet, como YouTube e Twitter. A formação de comunidades digitais e de amplas redes de interação levam a construções identitárias transculturais. Nelson Rodríguez Vega, em “La confluencia entre raperos chilenos y sellos discográficos multinacionales en la década de 1990: una operación con implicancias para el desarrollo del hip-hop en Chile", analisa a relação entre os artistas do rap/hip-hop chilenos e os selos fonográficos multinacionais. $\mathrm{O}$ autor demonstra que a indústria cultural não inibe ou neutraliza a função social dessa modalidade musical e seu potencial crítico. Ao contrário, pode funcionar como espaço estratégico que permite a ela ampla visibilidade do gênero.

\section{Etnografia da música - teoria e método}

Renan Moretti Bertho, no texto "A flauta e a câmera: usos e funções da imagem em uma etnografia da música", reflete sobre sua experiência ao estudar uma roda de choro na condição de músico e pesquisador. $\mathrm{O}$ foco do artigo é avaliar a eficácia do uso da imagem fotográfica no trabalho de pesquisa, recurso metodológico que lhe possibilitou a inserção no grupo e a negociação de posições de estar, ao mesmo tempo, dentro e fora da prática musical. A pesquisa realizada a partir do diálogo entre etnomusicologia e antropologia visual proporcionou ao autor revelar aspectos da roda de choro que vão além da dimensão puramente musical, como a interação e a sociabilidade dos participantes.

Esperamos que este conjunto de artigos que escolhemos para compor a seção temática desta edição traga contribuições para as pesquisas acadêmicas de música popular. 